\title{
The Palaeolithic of Seimarreh Valley in the Central Zagros, Iran
}

Mohsen Zeynivand ${ }^{1, *}$, Saeid Bahramiyan ${ }^{2} \&$ Khodakaram Mazaheri $^{3}$

Newly discovered prehistoric sites in the Seimarreh Valley in Iran provide the first evidence for Palaeolithic human habitation in this region of the Central Zagros.

Over the past few decades, Iran has frequently been considered the connecting bridge between South-western, South-eastern, Central and Eastern Asia, and a significant migration path for Pleistocene human dispersals (Bar-Yosef 1994; Biglari \& Shidrang 2006; Vahdati Nasab et al. 2013). Most studies of Palaeolithic Iran have been carried out by foreign archaeologists, and have concentrated on the Central Zagros (e.g. Braidwood et al. 1961; Hole \& Flannery 1967; Mortensen 1993). Although Iranian archaeologists (e.g. Biglari et al. 2000; Roustaei et al. 2004) have followed the same trend in recent decades, there are still unknown prehistoric sites throughout this region. The Seimarreh Valley is one of the least known regions of the Central Zagros, particularly in terms of prehistoric archaeology; compared to other regions, such as Mahidasht and Chamchal, the Seimarreh Valley has been mostly neglected. A survey of the Valley by Zeynivand in 2011 identified a complex of caves and rockshelters containing Palaeolithic artefacts. Consequently, more sites were identified in 2015 after a new approach to surveying was adopted. This provided new data indicating the importance of the Seimarreh Valley during the Pleistocene era.

\section{Geography and archaeological background}

The Seimarreh Valley is located in central Darre-Shahr County, in Ilam Province. The strategic location of the area as the connecting link between the Central Zagros, Mesopotamia and the Khuzistan Plain (Figure 1) has played a major role in interregional cultural exchanges. Furthermore, environmental resources, such as an abundant water supply (e.g. the Seimarreh River), and the existence of natural fortifications (e.g. the Kabirkuh and Mahle Mountains) (Figure 2) have attracted various human groups throughout history and prehistory. Following survey work in 2010, Zeynivand (2013) reported the first evidence for Pleistocene human activity in this valley. This initiated Palaeolithic studies in the region, and was followed by further survey in 2015 .

\footnotetext{
Department of Archaeology, Art University of Isfahan, Hakim Nezami Street, Isfahan, Iran Department of Archaeology, University of Tehran, Enqelab Street, Tehran, Iran

Department of Archaeology, Islamic Azad University of Ilam, Daneshjoo Boulevard, Ilam, Iran

Author for correspondence (Email: zeynivand@gmail.com)
} 


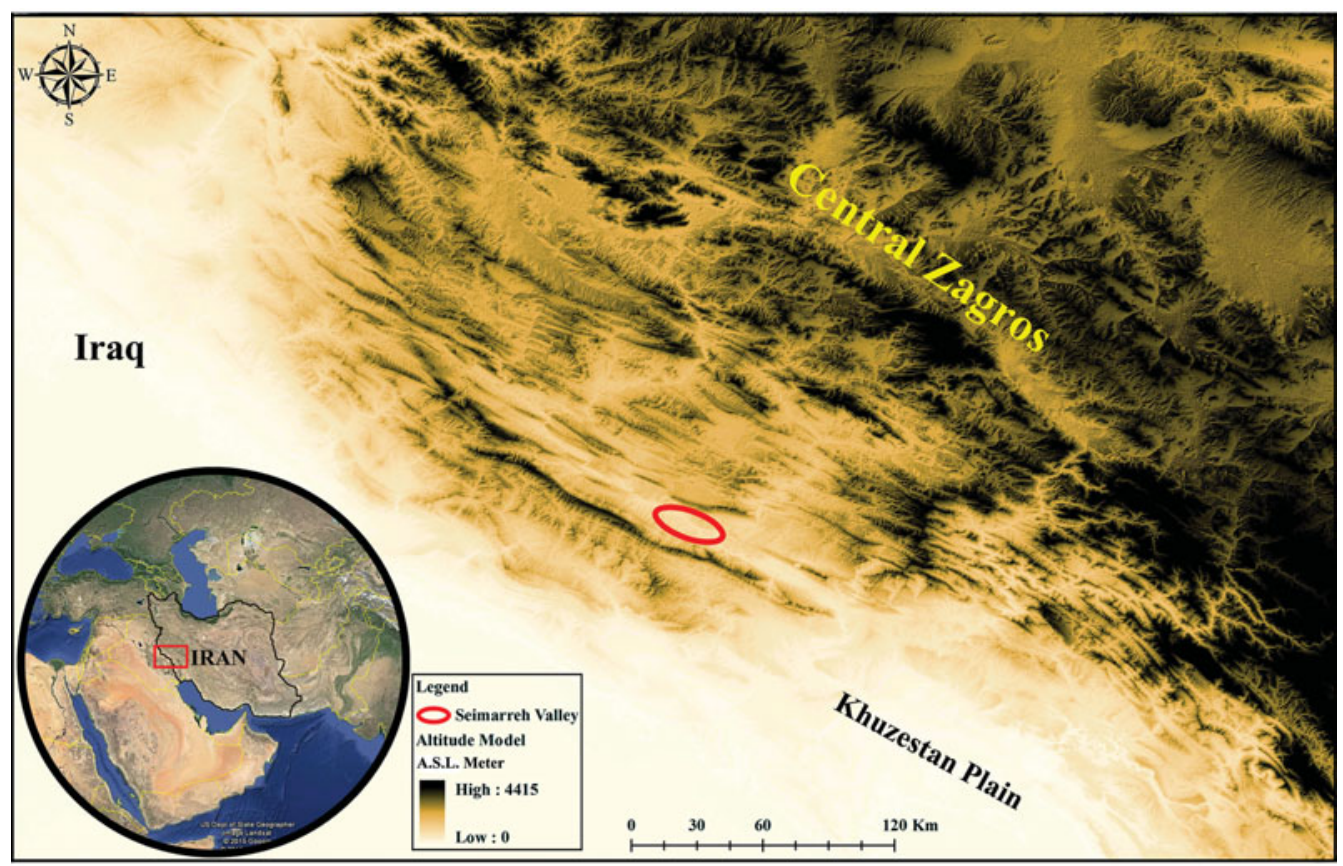

Figure 1. Geographic location of the Seimarreh Valley (GIS map by Saeid Bahramiyan).

\section{Survey and landscape}

Our priority before beginning the 2015 survey was to form a competent and reliable understanding of the Valley's landscape and topography, combined with an examination of the extant archaeological and geological literature covering the area. Geological studies record a remarkably large landslide, which occurred during the early Holocene in the western part of Seimarreh Valley and on the eastern side of Kabirkuh. Known as 'The Great Landslide of Seimarreh', it is considered to be one of the world's biggest landslides (Harrison 1946: 62; Oberlander 1965; Roberts 2008: 6). Its debris blocked the course of the Seimarreh and Kashkan Rivers in the north-eastern part of Kabirkuh and formed a natural dam and the subsequent great lake of Seimarreh. This submerged major parts of the Valley (Ambraseys \& Melville 1982; Roberts 2008; Shoaei 2014) (Figure 3). Eventually, the rivers broke through the dam and the lake was drained, leaving behind accumulated alluvial deposits. Due to the depth of this alluvium, the areas of the Valley with higher elevations have received more research attention. The 2015 survey discovered a number of Palaeolithic sites located at an altitude of $650-770 \mathrm{~m}$ asl and higher than the current valley's ground surface (Figure 4). These sites include the Kal-Esbi rockshelter, the Gar-eAlisafar and Pasgah open-space sites, and the Gar-e-Galis complex. The latter (Figure 5), comprising two caves and three rock shelters, is the most important site as an integrated complex based on the closeness of the sites and morphological and technological similarity of the artefacts.

(C) Antiquity Publications Ltd, 2018 


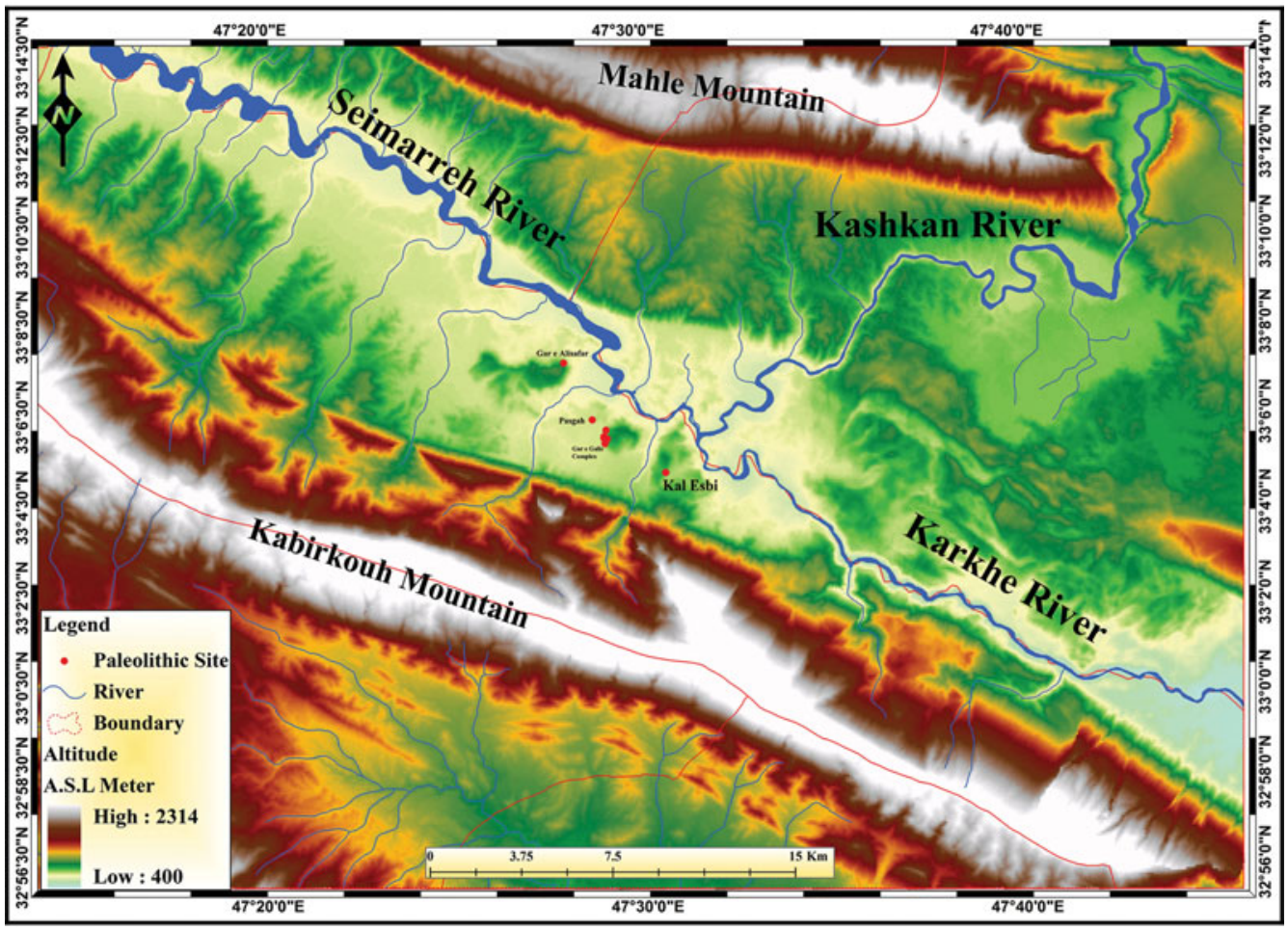

Figure 2. Map of Seimarreh Valley and distribution of Palaeolithic sites (GIS map by Saeid Bahramiyan).

\section{Artefacts}

Most of the recovered artefacts are from the Gar-e-Galis complex (61 pieces) and Gare-Alisafar (37 pieces), while Kal-Esbi and Gar-e-Pasgah yielded 25 fragments of stone tools. All of the discovered Palaeolithic sites in the Seimarreh Valley contained flake/blade cores and bladelet cores, debris, debitage (unused blanks) and tools. In rare cases, the use of the Levallois technique has been recorded. The tools vary between retouched pieces, scrapers, notches/denticulates and borers (only 1 piece). Over 90 per cent of the debitage results from a flaking technique, which detached small flakes from the cores (Figure 6). Approximately 70 per cent of the debitage has plain and cortical platforms, revealing that the core had not been properly prepared for producing flakes, flake tools or microliths. The presence of notches and denticulates, scrapers, the use of the Levallois technique and the implementation of the flaking technique all suggest that the sites were occupied during the Middle Palaeolithic period. The presence of one perforator fragment and six blade and microlith pieces should not, however, be discounted. Given the dearth of Middle Palaeolithic evidence in the Zagros Moutains, such as double-sided and convergent scrapers or Mousterian points, or evidence from more recent periods, such as end-scrapers, burins, retouched blades and Dufour microliths, the chronology of the newly discovered Seimarreh Valley sites must be considered very cautiously. 


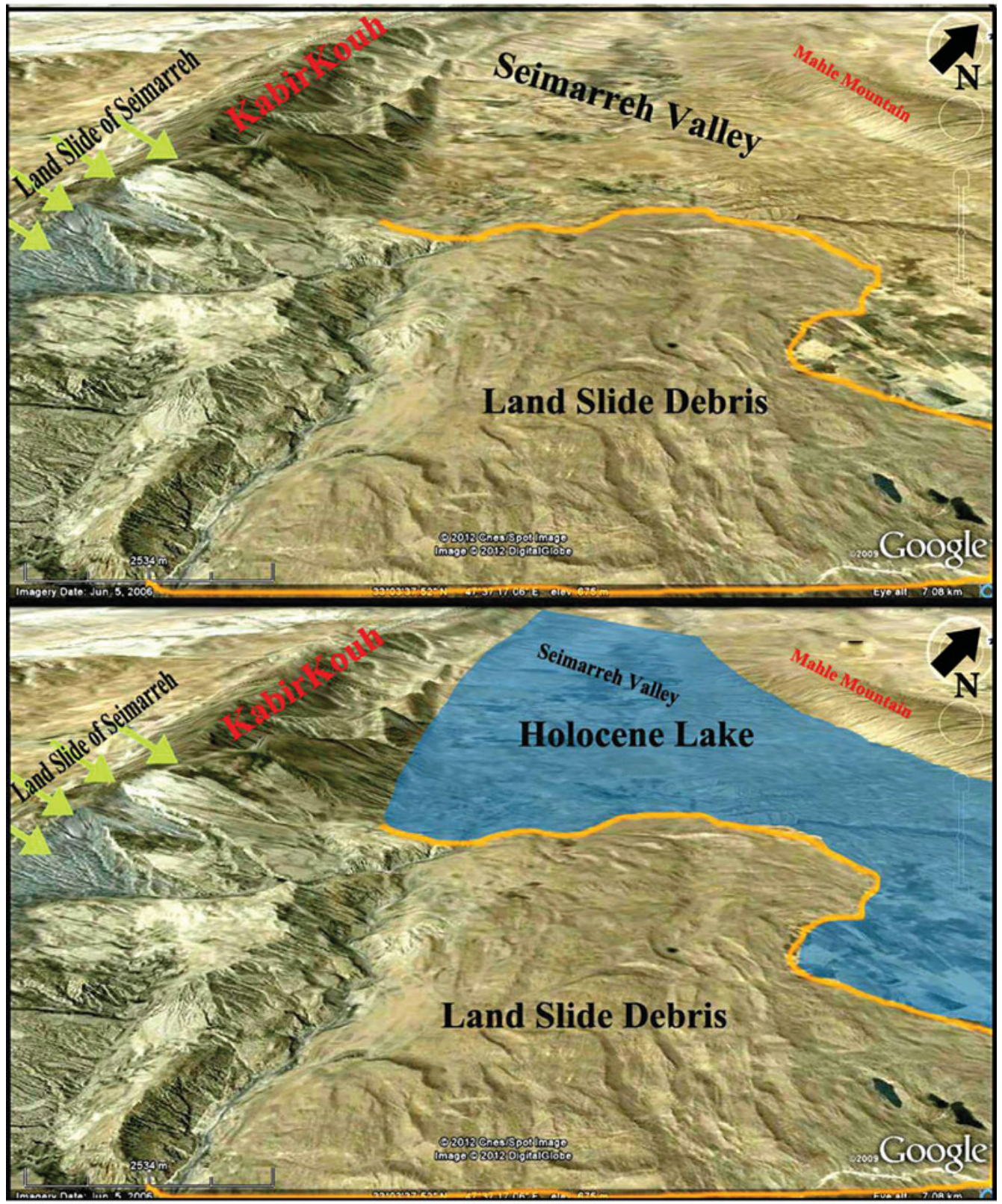

Figure 3. Top: location and direction of the landslide (green arrows); bottom: formation of natural dam.

\section{Conclusion}

Given the suitable environmental conditions and strategic geographic location of the Seimarreh Valley, it is surprising that no Palaeolithic site was found during two seasons of intensive survey. In 2015, however, a more precise survey based on geological studies (C) Antiquity Publications Ltd, 2018 


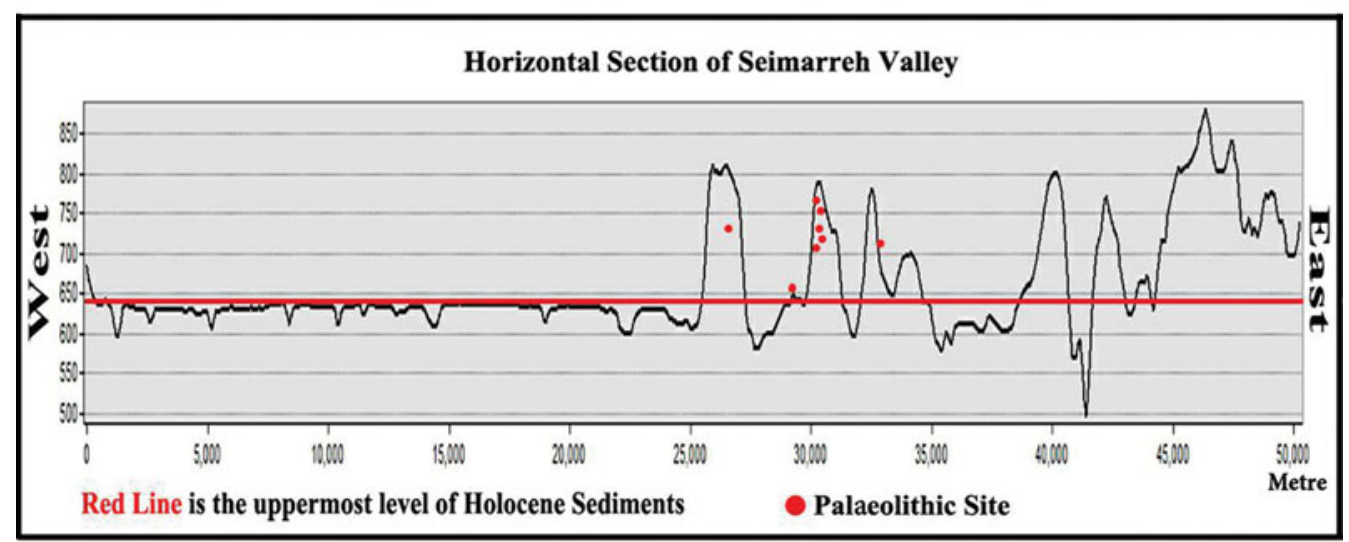

Figure 4. Histogram of Seimarreh Valley elevations and altitude of Palaeolithic sites.

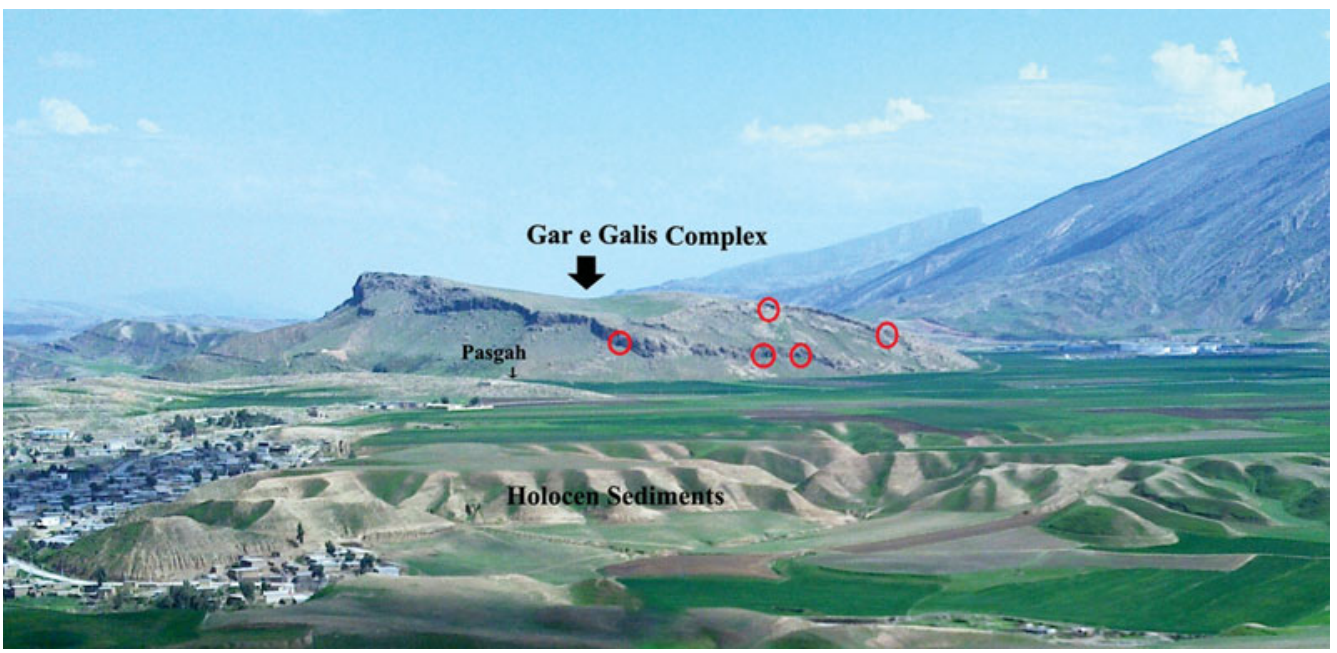

Figure 5. View of the Gar-e-Galis complex and the landscape of Seimarreh Valley, looking north (photograph by Mohsen Zeynivand).

confirmed evidence of a landslide, which had changed the morphology of the Seimarreh Valley and buried earlier sites under thick alluvial sediments. By focusing on areas higher than the current valley's ground surface, we discovered Palaeolithic occupation sites in rocky outcrops above the Holocene landslide deposits. 


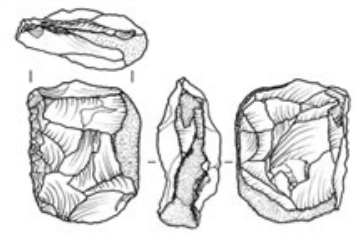

1

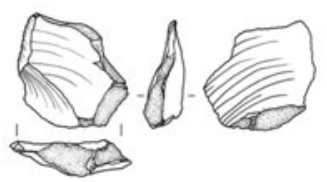

4

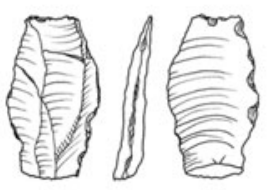

7

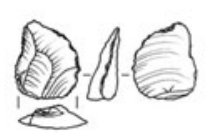

10

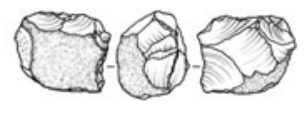

2

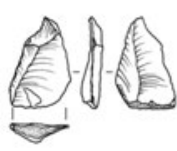

5

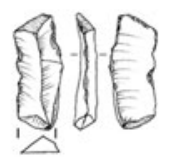

8

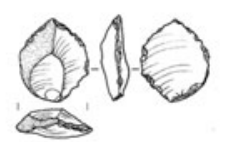

11

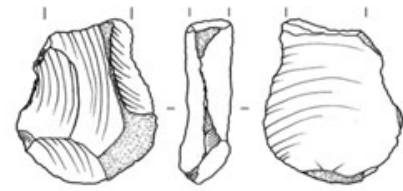

3
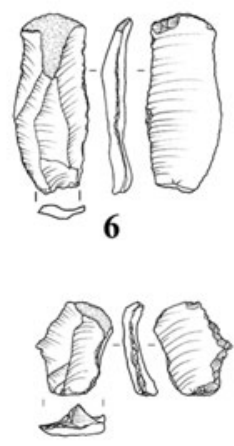

9

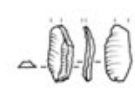

12

Figure 6. Some of the collected artefacts: 1-2) cores; 3-5) blank flakes; 6) single side scraper; 7-8) alternate denticulates; 9) borer; 10-11) retouched small flakes; 12) bladelets (artefacts $6 \& 7$ show use of the Levallois technique; drawing by Saeid Zeynali).

\section{References}

Ambraseys, N.N. \& C.P. Melville. 1982. A history of Persian earthquakes. Cambridge: Cambridge University Press.

BAR-Yosef, O. 1994. The Lower Palaeolithic in the Near East. Journal of World Prehistory 8: 211-65. https://doi.org/10.1007/BF02221050

Biglari, F. \& S. Shidrang. 2006. The Lower Paleolithic occupation of Iran. Near Eastern Archaeology 69: 160-68.

Biglari, F., G. Nokandeh \& S. Heydari Guran. 2000. A recent find of a possible Lower Paleolithic assemblage from the foothills of the Zagros Mountains. Antiquity 74: 749-50. https://doi.org/10.1017/S0003598X00060257

(C) Antiquity Publications Ltd, 2018
Braidwood, R., B. How \& C.A. Reed. 1961. The Iranian Prehistoric Project. Science 133: 2008-2010. https://doi.org/10.1126/science.133.3469.2008

Harrison, J.V. 1946. South-west Persia-a survey of Pish-I- Kuh in Luristan. Geographical Journal CVIII: 55-71. https://doi.org/10.2307/1789331

Hole, F. \& K. Flannery. 1967. The prehistory of southwestern Iran: a preliminary report. Proceedings of the Prehistoric Society 38: 147-206.

Mortensen, P. 1993. Palaeolithic and Epipalaeolithic sites in the Hulailan Valley, northern Luristan, in D.I. Olsweski \& H.L. Dibble (ed.) The Palaeolithic prehistory of the Zagros-Taurus: 159-87.

Philadelphia: University of Pennsylvania. 
Oberlander, T. 1965. The Zagros streams: a new interpretation of transverse drainage in an orogenic zone. Syracuse (NY): Syracuse University Press.

RoberTs, N.J. 2008. Structural and geologic controls on gigantic $\left(>1 \mathrm{Gm}^{3}\right)$ landslides in carbonate sequences: case studies from the Zagros Mountains, Iran and Rocky Mountains, Canada. MA dissertation. University of Waterloo, Canada.

Roustaei, K., H. Vahdati Nasab, F. Biglari, S. Heydari, G.A. Clark \& J.M. Lindly. 2004. Recent Paleolithic surveys in Luristan. Current Anthropology 45: 692-707. https://doi.org/10.1086/425636
ShoAeI, Z. 2014. Mechanism of the giant Seimareh landslide, Iran, and the longevity of its landslide dams. Environmental Earth Sciences 72: 2411-22. https://doi.org/10.1007/s12665-014-3150-8

Vahdati Nasab, H., G.A. Clark \& S. Torkamandi. 2013. Late Pleistocene dispersal corridors across the Iranian Plateau: a case study from Mirak, a Middle Paleolithic site on the northern edge of the Iranian Central Desert (Dasht-e Kavir). Quaternary International 300: 267-81. https://doi.org/10.1016/j.quaint.2012.11.028

ZeYnivand, M. 2013. A reconsideration of Seimarreh Valley in prehistory; from the beginning to the end of the Chalcolithic Period. Unpublished MA dissertation, Islamic Azad University, Central Tehran Branch (IAUCTB) (in Persian). 